\title{
Marcos legais e redes de contrabando de agrotóxicos: análise escalar a partir da fronteira Brasil-Uruguai
}

\author{
Marco legal y las redes de contrabando de agroquímicos: \\ análisis escalar a partir de la frontera Brasil-Uruguay
}

\section{Legal framework and agrochemicals smuggling networks: scale analysis from the Brazil-Uruguay border}

\author{
Adriana Dorfman \\ adriana.dorfman@ufrgs.br \\ Universidade Federal do Rio Grande do Sul \\ Arthur Borba Colen França \\ arthurborba@outlook.com \\ Universidade Federal do Rio Grande do Sul \\ Guilherme de Oliveira Soares \\ guimsoares@gmail.com \\ Universidade Federal do Rio Grande do Sul
}

\begin{abstract}
Resumo: Este texto discute a definição dos marcos legais e barreiras comerciais no comércio internacional de agrotóxicos. Ainda que a distinção entre legal e ilegal seja clara, o arcabouço regulatório não é estático, mas renegociado conforme demandas de diferentes grupos. A partir da descrição do mercado e de sua regulação, rotas de contrabando, territórios em rede e permeabilidades fronteiriças são mapeados e analisados. Conclui-se que os agentes atuantes na construção das leis não se limitam por elas, realizando ações ora legais, ora ilegais. Nesse deslizamento, a territorialidade estatal é instrumentalizada através de nacionalismos de empresas transnacionais, que recorrem à fronteira para construir o valor legal e mercadológico do agrotóxico.
\end{abstract}

Palavras-chave: Contrabando. Agrotóxicos. Comércio internacional. Fronteira. BrasilUruguai.

Resumen: Este artículo discute la definición de las barreras legales y comerciales en el comercio internacional de agroquímicos. Aunque la distinción entre legal e ilegal es clara, el marco regulatorio no es estático pero renegociado conforme las demandas de los diferentes grupos. De la descripción del mercado y su regulación, las rutas de contrabando, territorios en rede y permeabilidades de la frontera son mapeados y analizados. Se concluye que los agentes involucrados en la construcción de las leyes no están limitados por ellas, realizando acciones legales a veces, a veces ilegal. En este dispositivo, el Estado territorial es manipulado a través del nacionalismo de las empresas transnacionales que utilizan la frontera para construir el valor jurídico y comercial de los agroquímicos.

Palavras-clave: Contrabando. Agroquímicos. Comercio internacional. Frontera. BrasilUruguay. 


\begin{abstract}
This paper discusses the definition of the legal framework and trade barriers in the international trade of pesticides. Although the distinction between legal and illegal is clear, the regulatory framework is not static and is renegotiated according to the demands of different groups. This paper maps and analyzes the market and its regulation, smuggling routes, the network in territories, and the permeability of the border. We conclude that the agents involved in the construction of laws are not limited by them and that they perform actions that are both legal and illegal. In this slippage, the territoriality of the state is influenced by the nationalism of corporations which use the border to increase legal and market value of pesticides.
\end{abstract}

Keywords: Smuggling. Pesticides. International trade. Border. Brazil-Uruguay.

\title{
INTRODUÇÃO
}

O texto que segue apresenta uma discussão sobre a definição dos marcos legais e das barreiras comerciais no comércio internacional de agrotóxicos. Tal preocupação parte do estudo sobre o contrabando de agrotóxicos no Cone Sul. Há um limite claro entre o mercado legal e o ilegal, ainda que abordemos aqui práticas que transitam entre essas duas categorias. Salientamos os agentes envolvidos na permanente negociação sobre o permitido e o proibido no comércio de defensivos agrícolas em Sant' Ana do Livramento, RS, (fronteira gaúcha), no Brasil, no Uruguai, no âmbito do Mercosul e na escala global. Diferentes agentes tomam parte na definição da legislação sobre agroquímicos e em sua implementação: legisladores, agentes repressores de diferentes alçadas, agentes do mercado e do sistema internacional, indústrias de defensivos agrícolas, cientistas, movimentos camponeses, ecologistas, imprensa, contrabandistas, entre outros.

Partindo da descrição do mercado e de sua regulação, mapearemos e analisaremos algumas rotas de contrabando, indicativas de vantagens possíveis, de territórios em rede e de permeabilidades fronteiriças. A ideia de ordem normativa é trazida à baila a fim de enfatizar a negociação multiescalar e multilateral das normas que distinguem contrabando e comércio internacional. Tratamos ainda de discutir o papel desses agentes na formulação dos regimes legais e de legitimidade que recobrem os territórios estatais e a região formada pelo Mercosul, no que tange ao mercado internacionalizado de agrotóxicos.

A discussão se faz com foco nas escalas geográficas como um instrumento para examinar o lugar em sua posição relativa, ou situação, diante de um espaço mais amplo, um conjunto maior, permitind compreender polarizações e trocas. Como principal referência no campo da metodologia temos o texto de Rancine, Raffestin e Ruffy (1983), que afirma que é necessário praticar um "esquecimento coerente", um recorte no conjunto dos elementos reais, de acordo com fins, e postula que: 1) a escala geográfica exige uma teoria compatível; 2) ela permite diferentes graus de generalização ou detalhe, em que a agregação ou a atomização são falaciosas; 3) a escala depende tanto da intenção quanto da ação em pauta; 4) a escala geográfica condiciona as representações, revelando ou não os atributos dos objetos, reconhecendo ou não territórios e práticas. 
Nesta discussão, não opomos métodos quantitativos e qualitativos: no estudo do contrabando é difícil obter dados mais generalizáveis, que permitam tratamento estatístico. Além disso, não há análise estatística sem interpretação, ainda mais no tema em estudo, fortemente marcado por comunidades discursivas com posicionamentos opostos. Sem abrir mão da representatividade afiançada pela quantificação, a relevância de certos depoimentos individuais garante ao método qualitativo a produção de resultados significativos.

\section{BALIZANDO A DISCUSSÃO}

Agrotóxico é o nome utilizado, no Brasil, para uma vasta gama de produtos destinados a "defender" as plantas de seus predadores naturais e "ervas daninhas". Por esta razão, também são chamados de defensivos agrícolas. A fabricação e utilização destes produtos remonta à I Guerra Mundial, porém, é a partir da II Guerra que o investimento na produção e marketing de agrotóxicos cresce, integrando a chamada "revolução verde".

A terminologia oscila entre agrotóxico, agroquímico, defensivo, veneno, remédio, pesticidas, pesticides, entre outros termos que representam projetos distintos. Cada um desses termos carrega em si o posicionamento e as intenções da comunidade discursiva que gera o discurso, quais sejam: 1) a comunidade discursiva predominantemente ligada às empresas produtoras de agrotóxicos e às suas associações; 2) a comunidade discursiva predominantemente ligada a grupos ecologistas, de segurança alimentar, de direitos dos consumidores etc.; 3) a comunidade predominantemente engajada na produção de discursos científicos; 4) a comunidade do espaço midiático, que oscila entre as expressões condenatórias e as laudatórias; 5) a comunidade definida pelos integrantes dos órgãos de repressão ao contrabando e, finalmente, 6) a comunidade praticante do contrabando.

A legislação reflete o estado do debate. Deve-se observar que o termo inglês "pesticide" não necessariamente equivale ao termo "pesticida" em português, que se refere ao combate de pragas animais. A OMS e outros órgãos internacionais utilizam o termo pesticide como "substâncias utilizadas para eliminar pragas, sejam elas insetos, roedores, fungos e outras plantas". Chamaremos de agrotóxico aos produtos conhecidos internacionalmente como pesticides ou agrochemicals (WHO, 2012).

\section{O MERCADO BRASILEIRO DE AGROTÓXICOS}

O mesmo projeto que informa a eleição de um ou outro termo para designar as substâncias aqui discutidas influi na produção de dados estatísticos. O Brasil é o maior consumidor mundial de agrotóxicos, ainda que a afirmativa suscite discussão. No sítio da Associação Nacional de Defesa Vegetal pode-se ler: “O Brasil é o maior mercado consumidor de defensivos agrícolas? Não. Embora o controle de pragas na agricultura tropical requeira muito maior uso de defensivos agrícolas, o consumo no Brasil é muito menor que o observado em outros países." Citando um estudo de acesso restrito do Kleffmann 
Group, de 2007, afirma-se também que “o Brasil apresenta um dos menores investimentos por tonelada produzida e por área plantada" e que "no Brasil, o consumo, por unidade de área, foi de US\$ 88/ha, e por produção US\$ 7,4/t. No Japão, respectivamente, foi de US\$ 851/ ha e US\$ 73/t; na França, US\$ 197/ha e US\$22/t" (ANDEF, 2011a).

Já o Movimento dos Trabalhadores Sem-Terra, que organiza a "Campanha Permanente contra os Agrotóxicos e pela Vida", afirma que "O Brasil é o maior consumidor de agrotóxicos do mundo desde 2009", que "cada brasileiro consome em média 5,2 litros de agrotóxicos por ano" e ainda que "em 2009, foram comerciados legalmente 1 bilhão de litros. Distribuindo a quantidade de veneno utilizado chegamos à média de 5,2 litros de agrotóxicos por habitante ao longo do ano" (MST, 2011).

O uso estratégico dos dados permite chegar a todas essas verdades: o valor em dólares é realmente mais baixo no Brasil, onde os preços são muito inferiores aos dos países citados, mas o volume absoluto de agrotóxicos de fato é o mais elevado do mundo. Da mesma forma, o volume de agrotóxicos empregados dividido pela área plantada coloca o Brasil entre os países a utilizarem mais intensamente tais substâncias. Isso não quer dizer que os brasileiros consomem todo o agrotóxico aqui aplicado, uma vez que grande parte se destina às exportações.

Dados brutos são oferecidos por Ivan Amâncio Sampaio, segundo quem 725 mil toneladas de agrotóxicos foram comercializadas em 2009 e US $\$ 7,2$ bilhões de agrotóxicos legais foram consumidos pela agricultura brasileira em 2008 (SAMPAIO, 2011). Mesmo esses dados são de difícil análise, uma vez que não distinguem produtos técnicos (concentrados) e formulados (para a venda ao agricultor).

Em 2007, o mercado mundial de agrotóxicos era dominado por seis empresas, que controlavam 86\% das vendas dos produtos (Syngenta, Bayer, Dupont, Dow, Monsanto e Basf, segundo Hofmann et al, 2010). Esta realidade oligopolizada é atribuída ao grande investimento necessário em pesquisa e desenvolvimento.

Dado o volume e a importância do agronegócio, as empresas transnacionais supracitadas aqui se instalam. No Brasil, "o setor é liderado pelas 15 empresas associadas à Associação Nacional de Defesa Vegetal (Andef). São elas: Arysta LifeScience, Basf, Bayer CropScience, Chemtura, Dow AgroSciences, DuPont, FMC do Brasil, Iharabras, Isagro, ISK Biosciences, Monsanto, Nisso Brasileira, Sipcam Isagro Brasil, Sumitomo Chemical e Syngenta" (ANDEF, 2011b). Observe-se que grupos transnacionais são aqui identificados como indústrias nacionais: além das filiais de grande porte, incluindo laboratórios de pesquisa, estações experimentais e grandes unidades fabris com centenas de empregados, esses grupos possuem razão social brasileira e se apresentam à opinião pública nacional como empresas globais com ações no Brasil.

Outro dado relevante no mercado brasileiro de agrotóxicos é a recente entrada da Índia e da China, como mostra o substancial aumento nas importações da Índia (de 22 toneladas em 2001 para 4.595 toneladas em 2010, entre produtos técnicos e produtos formulados) e da China (de 2.109 toneladas em 2001 para 32.911 toneladas em 2010). A importação da Argentina, que passou de 1.352 toneladas em 2001 para 33.765 toneladas em 2010 (SAMPAIO, 2010) deve-se à vinda do glifosato usado nas plantações de soja, mostrando uma articulação do setor na escala do Mercosul. 


\section{O CONTRABANDO E O CONTRABANDO DE AGROTÓXICOS NO BRASIL}

Cesare Beccaria, jurista milanês do séc. XVIII, analisou a relação entre mercado, governo, tributos e controle aduaneiro:

Quando o rei exige um tributo sobre as mercadorias que entram ou saem, normalmente impõe a pena da perda da mercadoria submetida ao tributo a quem tentar evadi-lo. Portanto, o risco do reino é proporcional ao tributo e o do comerciante ao valor da mercadoria. Se o tributo é igual ao valor, os riscos são iguais para ambas as partes. Se o tributo for maior que o valor, o risco do reino é maior que o do comerciante. A isso se acrescenta que, se o risco do comerciante cresce em proporção aos guardas de aduana, diminui em proporção ao volume. (BECCARIA, 1822, p. 229. Tradução de Adriana Dorfman).

Do comentário pode-se concluir que o comércio legal ou ilegal é função da carga tributária, do custo da mercadoria e das iniciativas de repressão à evasão fiscal. Ainda hoje, tais elementos são centrais na manutenção das diferenciações de mercado com base em barreiras (não) tarifárias, mas a naturalidade com que o jurista italiano trata esse continuum parece ter desaparecido.

A importação ilegal de agrotóxicos para o Brasil é tornada atrativa pelo grande diferencial de preços, que pode chegar a 1/5 ou mesmo 1/10 dos valores praticados internamente. O diferencial liga-se aos impostos cobrados no Brasil, à legislação considerada rígida (que implica em testes meticulosos e licenciamentos demorados) e, especialmente, à reserva de mercado garantida por altas taxas de importação. A qualidade dos produtos não pode ser aqui discutida. O diferencial de preços atrai comerciantes para o transporte transfronteiriço, apoiado em redes de confiança e em relações de força. $\mathrm{O}$ transporte de agrotóxicos é menos tolerado na região que tipos mais tradicionais de contrabando, mas a grande demanda nas áreas produtoras encoraja o surgimento de grupos que transportam o produto até as áreas agrícolas no oeste do Brasil. Além do Rio Grande do Sul, os estados brasileiros do Paraná, Mato Grosso do Sul, Mato Grosso e Goiás registram frequentes apreensões de contrabando (figura 1).

Apesar das grandes dificuldades na obtenção de dados sobre o contrabando de agrotóxicos, as pesquisas têm apontado para a existência de rotas que ligam os produtores da China e da Índia a países limítrofes ao Brasil, como Uruguai e Paraguai. Nestes territórios, a comercialização dos produtos pode ser legal, mas sua entrada no Brasil se fará burlando as barreiras sanitárias e fiscais estabelecidas por órgãos como a Receita Federal do Brasil e a Agência Nacional de Vigilância Sanitária e implementadas por diferentes polícias e fiscais. 
Figura 1- Geografia do contrabando de agrotóxicos no sul do Brasil.

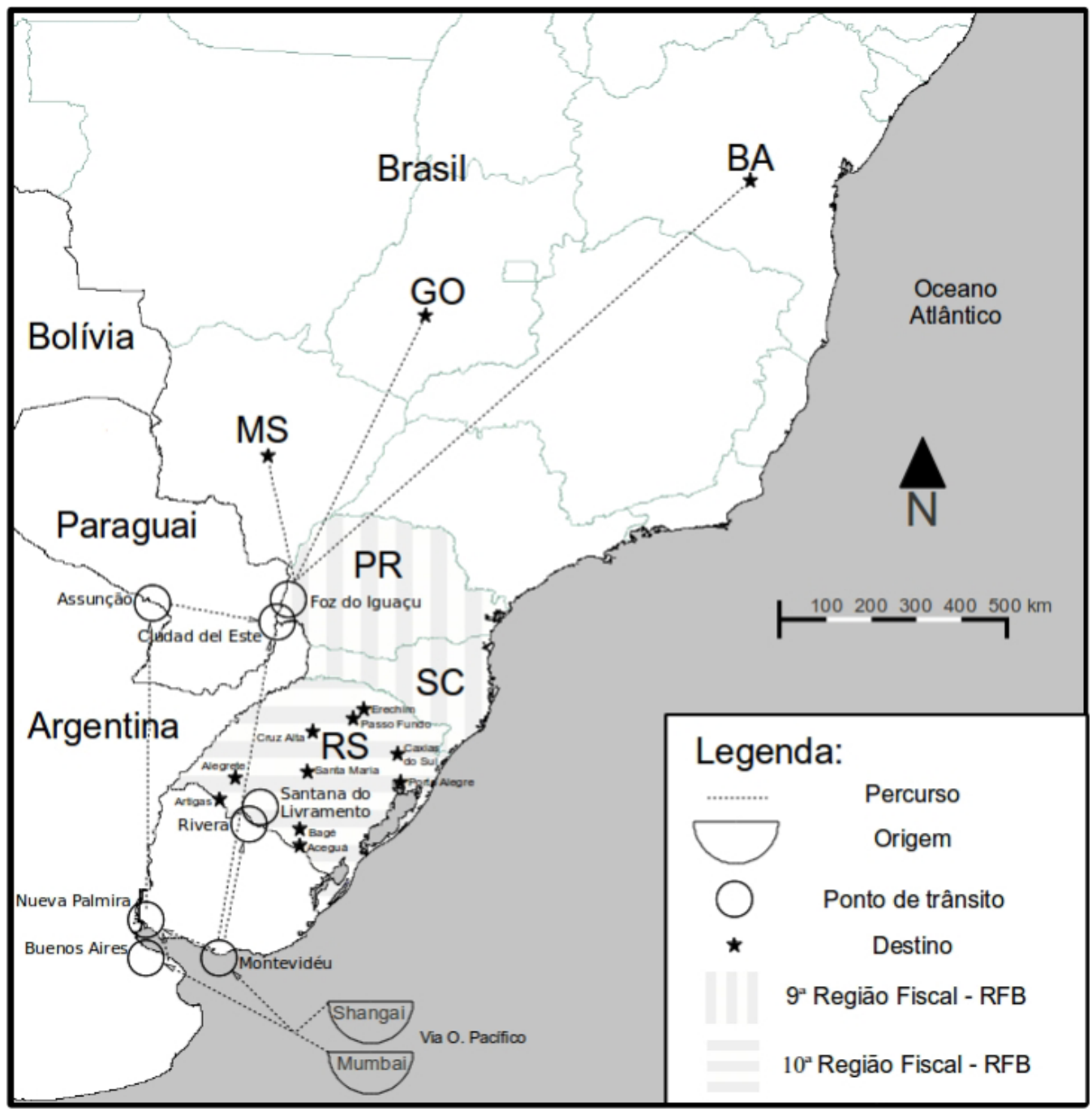

Fonte: DORFMAN, SEBASTIÃO, PRYTOLUK, 2011, p. 36.

Segundo dados da Receita Federal do Brasil, da Secretaria da Agricultura do Rio Grande do Sul e do Sindicato Nacional da Indústria de Defensivos Agrícolas, os agrotóxicos mais contrabandeados são diferentes apresentações dos princípios ativos metsulfuron e metsulfuron metil (herbicidas utilizados nas culturas de trigo, cevada, cana-de-açúcar e arroz), imidacloprid (inseticida empregado no tratamento de sementes de soja, milho, arroz, cevada e feijão), clethodim (herbicida usado na cultura da soja), carbendazin (fungicida usado no tratamento de sementes e em aplicação foliar no arroz, cevada, soja, hortaliças e girassol), tebuconazole (fungicida aplicado na sojicultura), e clorimuron e clorimuron etil (herbicidas usados na soja e em pastagens).

Em Sant'Ana do Livramento, basta atravessar a rua para cruzar a fronteira e ter acesso às agropecuárias uruguaias em Rivera, que oferecem diversos tipos de agrotóxicos, alguns proibidos no Brasil, caso do Herbex (metsulfuron metil), herbicida utilizado em culturas de arroz, soja, trigo, aveia e cevada. Mesmo constituindo crime ambiental e crime de contrabando e/ ou descaminho, arriscando verem suas lavouras destruídas, os ganhos econômicos com a compra de agroquímicos no Uruguai levam muitos agricultores a 
usar agrotóxicos ilegais. Algumas vezes são marcas chinesas e indianas que visam substituir os produtos encontrados no Brasil ("genéricos"), outras vezes são produtos de referência de empresas transnacionais legais no Brasil, mas importados via Uruguai, o que os torna irregulares no Brasil. Outro ponto importante a ser observado é que o contrabando de agrotóxico mobiliza redes que extrapolam o limite do local. Conversas com transportadores revelaram que existem sistemas para permitir pagamentos de forma segura, transportes pré-agendados com rotas cartografadas e um esquema que conecta os moradores de Livramento àqueles que fazem as encomendas em estados no centro do Brasil. Tanto a rede de confiança quanto o uso do produto ilegal, portanto, transcendem a fronteira, conforme informam entrevistados (Entrevista, Livramento, 2011).

Dessa forma, as escalas geográficas e econômicas que entram em relação aqui incluem o território brasileiro e de outros Estados, o Mercosul e o mercado global. Devem ser analisadas, assim, as estruturas jurídicas e ordens normativas correspondentes às diferentes escalas.

\section{A APLICAÇÃO DAS NORMAS E AS ESCALAS GEOGRÁFICAS}

É importante relembrar a distinção entre fronteira internacional e barreira comercial. A formação de blocos econômicos, por exemplo, a União Europeia, o Nafta e o Mercosul, representa somente a retirada de algumas das funções das fronteiras, em relação a Estados-nação selecionados, de maneira nenhuma significando a abolição das mesmas. Cláudio Egler observa que a lógica do capital financeiro é criar o maior espaço econômico possível, a seguir, transformá-lo em um território econômico protegido por limites que se traduzem em barreiras alfandegárias, o que garantiria sua exploração por associações monopolistas nacionais (2006). Aplicando esse raciocínio ao capital produtivo, o que aparenta ser uma barreira ao livre e liberal movimento econômico é transformado em vantagem por empresas transnacionais e por seus associados nacionais. Assim, o comércio internacional de agrotóxicos está regulado por barreiras comerciais que podem ser divididas em barreiras tarifárias e não-tarifárias (técnico-sanitárias), e que se expressam como diferenças no preço, câmbio, legislação sanitária, de qualidade e oferta. A exploração dessas diferenças motiva o contrabando.

São justamente essas diferenças que devem ser problematizadas. As normas, que variam na escala global, regional, nacional e local, também variam em grau de obrigatoriedade e em possibilidades de sanção. É característica das normas internacionais a grande abrangência. Esses documentos, em sua maioria, recomendam aos Estados avançarem em suas próprias regulamentações, e não possuem caráter de lei. Apesar de serem apenas recomendações, mais incisivas ou não, os Estados cumprem praticamente todas as normas por eles assinadas, em quase todo o tempo, seja por fazerem parte do processo de elaboração, por acreditarem na legitimidade da norma ou por desejarem manter uma imagem de nação confiável e digna de negociação perante a comunidade internacional (SHELTON, 2003). 
O âmbito do Mercosul, no entanto, não necessariamente coincide com as características do nível de regulamentação global. Frequentemente, os Estados membros do bloco descumprem as normas por eles mesmo acordadas, o que acaba por gerar situações de crise diplomática. Mecanismos de solução de controvérsias são acionados regularmente, como mostram os exemplos nos parágrafos seguintes. As sanções são muito mais viáveis que em nível global, dado o grau de integração dos membros. Apesar de ter uma institucionalidade similar à da negociação do nível global, a regulamentação do Mercosul aparenta ser mais flexível, ou mais passível de descumprimento, porque, principalmente, não é desejo das partes tensionar em demasiado as relações. Existe a possibilidade de saída do bloco e de readaptação dos países a um novo contexto comercial, o que dificilmente seria possível em instituições como as Nações Unidas. Também não é desejo dos membros, justamente pela proximidade dos mesmos, criar uma zona de instabilidade ou conflito. Assim, mudanças de contextos e interesses motivam o descumprimento das normas, e os mecanismos protocolares são acionados sem que isso afete de forma impactante as trocas entre os Estados Membros.

A institucionalidade do Mercosul se baseia na existência de Estados territoriais e nas relações que podem ser estabelecidas entre os mesmos. Ainda que frequentemente se vincule a multiplicação de blocos econômicos às tendências globalizantes e à necessidade de ampliação da escala produtiva transnacionalizada, o sistema interestados fornece as bases para a integração. Cabe primeiramente diferenciar a quem se aplicam as normas. Nos dois primeiros casos, tratam-se efetivamente de entes estatais a serem controlados e, eventualmente, sancionados, enquanto no terceiro, são os cidadãos nacionais que se encontram submetidos à soberania estatal. Portanto, o poder coercitivo do Estado é significativamente maior que o do bloco, apoiando-se em um sistema jurídico e repressivo muito complexo, altamente formalizado, que busca regular todas as relações, sejam elas civis, comerciais, trabalhistas ou criminais, travadas pelos cidadãos no interior do território estatal.

Por fim, na escala local, da vizinhança, não se trata de regulamentos escritos, mas da construção da honra, da aceitação, do habitus. Ainda que, em casos limites, as sanções possam ser extremamente duras, é o convívio cotidiano que está em questão.

\section{NORMAS GLOBAIS PARA O COMÉRCIO DE AGROTÓXICOS}

Uma rápida busca no portal das Nações Unidas pelos termos "pesticides" ou "agrochemicals" revela um número expressivo de documentos versando sobre o tema. A maioria deles, no entanto, busca regular o uso e administração dos agrotóxicos na produção agrícola, tendo a saúde do consumidor final e dos próprios produtores como preocupação imediata. São poucos os que tratam do comércio internacional dessas substâncias.

Sobre esses últimos documentos, dois merecem atenção. Primeiramente, a chamada Convenção de Rotterdam, com escopo específico no comércio de pesticidas de uso restrito. O que deve se extrair do documento para a discussão deste artigo é que: (a) existe 
uma lista de substâncias restritas passíveis de comércio apenas em situações específicas, o que deve ser reportado à comunidade internacional; e (b) há a necessidade de que a substância importada/exportada esteja nos países de origem e destino (FAO, 1998). Brasil e Uruguai são signatários dessa Convenção.

Também digno de nota é o Código de Conduta Internacional da Distribuição e Uso de Pesticidas, aprovado igualmente pela FAO em sessão de 2002. A particularidade do documento é atribuir à indústria de pesticidas, e não aos Estados, a responsabilidade de zelar pela qualidade dos produtos inseridos no comércio internacional, que deve estar conforme uma série de recomendações do órgão. Também é responsabilidade dessas indústrias garantir que suas filiais produzam conforme as regulamentações internacionais, bem como se certificar da confiabilidade do importador (FAO, 2002). Surge a imputabilidade das empresas.

\section{REGULAÇÃO NO ÂMBITO DO MERCOSUL}

No que tange a barreiras técnico-sanitárias, o Mercosul, através de resoluções, vem procurando normatizar os trâmites de agroquímicos, comumente denominados "produtos fitossanitários" nos documentos do bloco, preocupando-se especialmente em harmonizar mecanismos de registro de substâncias nos países integrantes do bloco. A resolução 48, de 1996, determina as condições para que as substâncias possam ser consideradas de livre circulação, isto é, isentas de barreiras tarifárias. São os critérios principais: (a) que sejam produzidas no Mercosul; (b) que tenham seu uso autorizado e registrado pelos Estados partes; (c) que as substâncias ativas de grau técnico apresentem características idênticas ou extremamente similares à registrada; e (d) que a empresa produtora tenha representante legal no país de destino. A resolução também apresenta a Primeira lista de substâncias de livre circulação entre os Estados Partes do Mercosul, que contém treze princípios ativos (MERCOSUL, 1996a).

Regulamentações posteriores, como a resolução 87/96, preocupadas com a uniformidade do registro das substâncias, estabelecem a extensa lista de informações que devem ser depositadas nos órgãos responsáveis dos Estados Membros para obter o registro e a livre circulação dos produtos fitossanitários (MERCOSUL, 1996b). Outros documentos ampliaram a lista de substâncias classificadas como de livre circulação, dentre eles as resoluções 149/96, 156/96 e 71/98 (MERCOSUL, 1996c; MERCOSUL, 1996d, MERCOSUL, 1998).

Esta regulamentação do Mercosul já foi alvo de reclamações argentinas em relação a barreiras técnico-sanitárias impostas pelo Brasil. A barreira brasileira à importação de fitossanitários argentinos gerou uma disputa, resolvida através do mecanismo de solução de controvérsias do bloco, que teve seu laudo publicado em 2002, dando ganho de causa à parte Argentina (MERCOSUL, 2002). Pode-se observar aqui a tentativa de reserva de mercado por parte das transnacionais presentes no território brasileiro através da elevação de uma barreira técnico-sanitária, de modo que também as barreiras brasileiras expressam demandas das transnacionais. 
Quanto a barreiras estritamente tarifárias, o Brasil buscou estender à Argentina as barreiras comerciais previstas no acordo anti-dumping que barrou, entre 2003 e 2010, a entrada de glifosato chinês. O Ministério do Desenvolvimento, Indústria e Comércio Exterior do Brasil, amparado nos Acordos Anti-dumping da Organização Mundial do Comércio (OMC) e na lei 9095/95, assim define dumping: " quando uma empresa exporta para o Brasil um produto a preço (preço de exportação) inferior àquele que pratica para produto similar nas vendas para o seu mercado interno (valor normal)" (MDIC, 2012). O anti-dumping é a taxação de bens importados para igualar preço de exportação e valor normal, protegendo assim a indústria nacional. Além disso, o Mercosul também procura harmonizar a interpretação dos acordos anti-dumping dos Países Membros.

Há processos de contestação, que partem de denúncias do setor privado, nos quais se busca embargar a importação de glifosato sob a suspeita de ser produto de origem chinesa "nacionalizado" e não produzido na Argentina, numa operação de "triangulação", nos quais a passagem pela Argentina permitiria aceder a isenções de impostos dadas pela livre comércio objetivado pelo Mercosul. Dessa forma, observamos que a normatização do comércio internacional de agroquímicos passa pela pressão dos grupos privados, não podendo ser representadas simplesmente como embates entre países mais ou menos rigorosos ou liberais em quesitos ambientais. Podemos apontar como âmbitos legalmente estabelecidos para a discussão com agentes privados o Fórum para a Competitividade da Indústria dos Defensivos Agrícolas, formado em 2003, na esfera do Ministério do Desenvolvimento, Indústria e Comércio (MDIC, 2003).

\section{AS NORMAS VIGENTES NO BRASIL E NO URUGUAI}

A disputa pelo comércio e registro de agrotóxicos no Mercosul revela que a legislação comum ao bloco não é suficiente para suprir as diferenças jurídicas dos Países Membros. No Brasil, o comércio, registro ou punição por irregularidades referentes aos agroquímicos se faz pela Lei dos Agrotóxicos 7802/89, modificada posteriormente pela lei 9974/00. A presente lei determina, no artigo 13, que "a venda de agrotóxicos e afins aos usuários será feita através de receituário próprio” (DOU, 1989). Não é permitida, portanto, a compra autônoma de qualquer agroquímico. A legislação uruguaia difere substancialmente neste ponto. O Uruguai permite a venda de 1.121 marcas comerciais de agrotóxico e requer o receituário de apenas 39 delas (URUGUAY, 2009). O Uruguai utiliza a classificação de toxicologia de agroquímicos recomendada pela Organização Mundial da Saúde (OMS), partindo do International Programme on Chemical Safety, que agrupa os agrotóxicos em quatro categorias: Ia (produto extremamente perigoso), Ib (produto muito perigoso), II (produto moderadamente perigoso), III (produto pouco perigoso) e $\mathrm{U}$ (produtos que não costumam oferecer perigo) (WHO, 2009). O governo uruguaio requerer receituário no ato da venda apenas para os produtos classificados como Ia e Ib, de acordo com o decreto 482 de 19/10/2009.

A lei estabelece o que é contrabando, mas a decisão de reprimi-lo cabe aos diferentes agentes que controlam as fronteiras e o território nacional. Dada a impossibilidade de 
vigiar todas as mercadorias que transitam pelo país, são estabelecidas metas em volume de apreensões e em produtos específicos. No caso dos agrotóxicos, há no Brasil uma discussão que envolve sindicatos de produtores, agroecologistas e a sociedade em geral, condenando enfaticamente e demandando a repressão ao contrabando, estabelecendo, assim, essa meta. De fato, o principal promotor da campanha nacional de combate ao contrabando de agrotóxicos é o Sindicato das Indústrias Nacionais de Defensivos Agrícolas (DORFMAN; REKOWSKY, 2011).

Objetivamente, as apreensões de agrotóxicos contrabandeados não são volumosas. As campanhas anti-contrabando parecem funcionar mais na dissuasão dos agricultores, afastando-os da prática, ao mesmo tempo em que leva à especialização de contrabandistas, algumas vezes trabalhando em quadrilhas e atuando dentro, fora e em diversos estados do país, e movimentando grandes quantidades de produto e dinheiro. Temos como hipótese que a rede regional gaúcha construída pela incorporação de áreas agrícolas no oeste é um dos nexos desse comércio (HAESBERT, 1997).

Além disso, as campanhas transformam a percepção do contrabando. Como anteriormente dito, o contrabando é usualmente aceito como prática ilegal, mas legítima. O item agrotóxico, no entanto passa da indiferença à enfática condenação em algumas representações locais. As campanhas parecem ainda deslocar o entendimento do risco do uso de agrotóxicos, limitando o perigo aos produtos contrabandeados. Conversando com pessoas na fronteira, observa-se que a expressão agrotóxico passa a designar contrabando, enquanto o agroquímico produzido nacionalmente é chamado defensivo.

\section{AS NORMAS LOCAIS PARA O COMÉRCIO DE AGROTÓXICOS}

A diferença entre as legislações torna legal a compra sem receita no Uruguai, sendo considerado crime a introdução dos agrotóxicos no Brasil. Este é um dos motivos pelos quais é tão difícil combater o contrabando, e porque este é associado à região fronteiriça, vista como porosa. As revendas de agrotóxicos uruguaias operam legalmente ao oferecer centenas de produtos sem receita agronômica. Isso pode ser constatado ao se visitarem lojas agropecuárias, onde os produtos ficam expostos na calçada e nas prateleiras. Muitos comerciantes auxiliam os compradores brasileiros a passar com os agrotóxicos: possuem serviços de entrega ou conhecem os chamados "mulas", pessoas que cruzam a fronteira com os produtos ilegais de propriedade de terceiros, tornando o risco menor para quem os compra. Pode-se afirmar que a associação contrabando/região fronteiriça fronteiriça sublinha um dos nós da rede, uma vez que a motivação (a diferença de preço vigente em todo o território brasileiro) e o destino (as regiões agrícolas no oeste do Brasil) são de outra ordem escalar.

Em trabalho anterior, concluiu-se que o contrabando organiza lugares e é absolutamente estrutural na sociedade fronteiriça, no abastecimento e no sustento das pessoas, sendo aí visto mais como trabalho do que como delito, realizando-se através das redes de solidariedade indispensáveis à sua execução e legitimação. Além disso, o ethos contrabandista cria uma identidade de lugar, distinguindo outsiders e membros (cúmplices) 
do grupo, numa territorialidade com extensão, passagens e polarizações em constante atualização, dada a variabilidade dos conteúdos da fronteira (DORFMAN, 2009).

Entretanto, o contrabando de agrotóxicos aparece como um caso distinto. Uma das razões para tal é o volume das cargas, tratando-se de grandes caminhões que são dirigidos por "profissionais" e que implicam grandes valores de mercadoria e significativas contravenções. Em segundo lugar, o destino remoto das cargas (no Centro-Oeste do Brasil, por exemplo) liga redes extralocais onde a solidariedade é menos importante que as relações hierarquizadas. Junto à comunidade, sentem-se os efeitos das intensas campanhas movidas pelos produtores de agrotóxicos, criminalizando o contrabando, estimulando a repressão pelos órgãos policiais e criando uma separação entre os transportadores e a população local,

Nota-se que as normas locais regulam práticas que são, a princípio, ilícitas, mas que devem obedecer ao que pode ser chamado de um "código de conduta local". É senso comum, em Livramento, RS, que não se deve ostentar a riqueza acumulada com o contrabando, isto é, não aparecer, ir contra ou se afastar da comunidade: não se deve "dar na vista". A hibridação entre o legal e o ilegal vai mais adiante. Aquele que desrespeita a norma local po de sancionado, seja de forma ilícita, com uma morte simbólica e social, impossibilitando sua permanência no local e obrigando-o a se mudar, seja de forma ilícita, com até mesmo sua morte, de forma social, impossibilitando sua vida no local e obrigando-o a se mudar, tanto de forma legal, sofrendo denúncias e sendo processado judicialmente pelo crime de contrabando. Existe, então, uma continuidade entre legalidade e ilegalidade.

\section{A CENTRALIDADE DA MARGEM}

A discussão até aqui feita, partindo das escalas geográficas, pode ter causado a falsa impressão de que o objeto do estudo é uma das margens dos Estados do Brasil e Uruguai. Essa conclusão prévia não é de todo absurda. Ao perceber que as normas, conforme a escala, variam igualmente em oficialidade e grau de obrigatoriedade, percebe-se também que é a escala local que mais dialoga entre as categorias do legal e ilegal. Seria a fronteira Brasil-Uruguai, portanto, "terra sem lei"? Não é o caso. Faz-se necessário observar que a norma local acima discutida regula efetivamente as práticas sociais, mas o faz transitando entre o permitido e proibido pelos arcabouços jurídicos diversos. O que deveria ser uma norma única e soberana se converte em várias normas, condicionando diferentes estratégias perante a condição fronteiriça. Essa pluralidade de normas toma lugar diante das mais variadas instituições do Estado, e com elas se relaciona de forma que precisa ser discutida. Até que ponto, afinal, a fronteira é a margem?

Livramento-Rivera são noticiadas nas midia regionais e nacionais mais por apreensões de contrabando ou fatos incomuns do que por suas particularidades e potencialidades. No entanto, apesar de distante dos centros de decisão do país, Livramento abriga grande contingente militar, um grande prédio da Inspetoria da Receita Federal, a aduana integrada e incontáveis marcos, bandeiras e símbolos nacionais espalhados pelo perímetro urbano. Sua aparente marginalidade, portanto, pode ser questionada. A resposta a essa pergunta deve iniciar-se pela investigação do conceito de margem. 
O estudo sobre as margens nos permite visualizar como a multiplicidade de regulações, diversas vezes concorrentes, são necessárias para a formação do Estado, da mesma forma que a exceção é importante para compreensão da regra. Das e Poole, ao introduzirem três possibilidades de leitura, apresentam uma que cabe em nossa análise. A margem seria um espaço entre os corpos, a lei e a disciplina (DAS; POOLE, 2008), remetendo à biopolítica foucaultiana, e deve-se ter em mente que a regulação do Estado afeta os espaços e os corpos que o habitam, criando categorias de patologização. Indo além da patologia médica, pode-se compreender que certos repertórios práticos e estratégias de cidadania são patologizados na medida em que são percebidos como "parasitas da lei" (idem).

Avançando no raciocínio, as autoras também esclarecem que a margem é mais do que territorial, mas local de práticas nas quais a lei e outros procedimentos estatais são submetidos por outras formas agir que derivam das necessidades de determinada população de sobreviver política e economicamente (ibidem).

Ora, é a partir desse arcabouço que fica possível entender a fronteira Brasil-Uruguai como margem. A mídia de alcance nacional frequentemente evoca a categoria "contrabandista" de uma forma que poderíamos chamar de patológica, fato que não ocorre na localidade. A fronteira, se por uma escala é percebida como o local da ilegalidade, em seu contexto é percebida como local que possibilita estratégias que podem transitar entre legalidade e ilegalidade sem se inviabilizarem. É preciso, portanto, ter em mente esse caráter tanto de margem, pelo acima discutido, tanto de centro, dada a contingência de agentes do Estado presentes no local e o contato entre dois Estados, para compreender por que é possível, a partir da fronteira Brasil-Uruguai, derivar articulações que concernem tanto à localidade, e suas particularidades, ao âmbito nacional e ao comércio internacional.

Podemos listar como lugares do contrabando os "bazares" urbanos e as passagens, sem esquecer que o contrabando se utiliza reiteradamente da centralidade da margem. Primeiramente, explora a dualidade ilegal/legítimo das normas locais para efetuar-se. Menos evidente, porém, é o uso feito pelo contrabando da existência de um aparato urbano e estatal considerável. Se, em primeira análise, a existência de um centro urbano, que pode até mesmo ser visto como cosmopolita considerando sua localização, e a presença de agentes e estruturas oficiais poderia intimidar o comércio transfronteiriço ilegal, são esses mesmos fatores que o permitem. É interessante notar que as notícias de apreensão de contrabando pela Polícia Federal do Brasil, quando organizadas e cartografadas, revelam que os policiais fazem flagrantes em zonas habitadas, e os vazios demográficos também aparentam ser vazios comerciais e fiscais.

$\mathrm{O}$ fato é que o contrabando, especialmente o contrabando de agrotóxicos, precisa de caminhões, de estradas (mesmo que vicinais) que conectem a fronteira aos produtores agrícolas e de uma rede de pessoas que extrapola os limites locais. O contrabando de agrotóxicos, portanto, precisa de tecnologias, como a de transporte e comunicação e comunicação, que são fornecidas pelo Estado, e assim se faz valer da centralidade do nosso objeto. Não se deve ter em mente uma imagem romantizada do contrabandista desafiando todos os limites e transitando por lugares inabitáveis e intransponíveis com 
com sua carga. A verdade é que se a fronteira Brasil-Uruguai fosse uma completa margem, sem as estruturas fornecidas pelos governos nacionais, o contrabando provavelmente seria inviável. É de suma importância lembrar ainda que o contrabando, como comércio, realiza seu capital na entrega da encomenda ao cliente que se localiza distante da fronteira, por vezes a mais de dois mil $\mathrm{km}$ do passo fronteiriço.

\section{CONSIDERAÇÕES FINAIS}

Recapitulando, as diretrizes do WHO, as normas do Mercosul, as leis dos países e os costumes locais refletem a distribuição do poder entre os diferentes agentes envolvidos e as várias abrangências espacial e social, obrigatoriedade e objetos da norma. Cabe lembrar ainda que as normas dependem do sistema legal (tribunais e órgãos repressivos, principalmente) para tornarem-se balizamentos para a ação.

Um primeiro ponto a estabelecer é a diferença entre os sujeitos das leis, normativas e regras. O Código de 2002 da FAO imputa as empresas, sugere uma harmonização internacional das regras e julga em foro internacional as denúncias. As relações entre Estados e no âmbito do Mercosul se institucionalizam no sistema interestados: aqui os sujeitos são os Estados territoriais e a solução de controvérsias se fará por denúncias. Já as leis nacionais têm como objeto os cidadãos e as empresas e possuem grande aparato institucional para apoiar sua implementação. Pode-se postular que quanto mais abrangente a escala a que se aplica a norma, menor obrigatoriedade existirá na sua adoção, o que se relaciona com a dificuldade de ação das instituições de controle e repressão na escala mundial. Na escala local/prática cotidiana, as regras são também de ordem não institucional, com força de sanção.

As discussões que estabelecem marcos legais, tanto no âmbito nacional quanto no suprarregional, levam em conta as reivindicações dos setores produtivos, com "o objetivo de restringir a discricionariedade das autoridades investigadoras das práticas comerciais" (MDIC, 2003). Não descrevemos a ordem normativa como um conjunto estanque de leis ou como produto de um Estado monolítico. Conforme se mostrou, a definição da legislação sanitária e fiscal se faz através de uma rede de poder bastante ampla, em que vemos indústrias em busca de menor regulação se opondo a ecologistas e MST, que demandam o banimento ou, pelo menos, o controle estrito do uso de agrotóxicos; acompanhamos as diferentes posições da ANVISA e de comissões no Senado Federal a respeito das sanções a serem aplicadas etc. Ainda que sublinhemos o papel dos agentes privados internacionais na definição dos marcos legais e das barreiras comerciais brasileiras e, portanto, do que constitui contrabando de agrotóxicos, ou seu papel nas negociações no âmbito do Mercosul, tampouco descrevemos o Estado como mero executor dos ditames dos capitalistas.

A influência dos agentes privados internacionais na decisão de reprimir o contrabando de agrotóxicos no Brasil pode ser exemplificada pela campanha promovida pela associação das transnacionais instaladas no país. Já está bem estabelecido o poder discri- 
cionário de fiscais e agentes repressores, isto é, seu arbítrio na dureza da aplicação da lei e na definição das prioridades diante da incapacidade de reprimir todos os delitos e todos delinquentes, mas é importante notar que as campanhas contra o contrabando de agrotóxicos - movidas pelos sindicatos de produtores no Brasil e difundidas pela imprensa chamam a atenção da opinião pública, ampliando a repercussão positiva das apreensões. A repressão ao contrabando passa a tema de interesse público.

Um efeito secundário da campanha seria a introdução de uma diferenciação semântica entre agrotóxicos (que seriam os produtos contrabandeados) e defensivos (que seriam aqueles produzidos e comercializados legalmente) na escala local, conforme apontaram trabalhos de campo. O combate ao contrabando de agrotóxicos mobiliza imagens negativas associadas à fronteira, ao estrangeiro, reforçando zonas morais e criminalizando ou desvalorizando os produtos chineses e indianos, chamados pejorativamente de ching-ling ou classificados como sendo de segunda linha.

Além disso, o discurso da legalidade e ilegalidade nem sempre é compatível com os espaços e práticas por ele referidos. Essa incongruência é propositiva. A fronteira em questão, costumeiramente tratada como "porosa" e "permissiva", é frequentemente acusada de ser o espaço da ilegalidade. Diferentes comunidades discursivas defendem a necessidade de endurecer a fronteira, conter as passagens, em projetos que, em primeira análise, priorizam a segurança à integração, criando uma oposição entre esses dois momentos.

Como vimos, o contrabando não se restringe à passagem de fronteiras internacionais, sendo uma prática que se mostra possível na escala local (na região fronteiriça), se realiza na escala regional (áreas de produção agrícola) e é motivado por diferenças de preço e legalidade (na escala nacional) estabelecidas em acordo com agentes de diferentes setores (inclusive transnacionais).

Além disso, os maiores ilegalismos acontecem nos grandes centros de decisão e nas áreas produtoras mais centrais. São eles os concentradores de práticas que diminuem consideravelmente o orçamento público e as possibilidades de promoção do bem-estar pelo Estado. Os movimentos do capital financeiro e as dinâmicas de manipulação dos cofres públicos, por exemplo, são muito mais "porosos" e "permissivos" que o fluxo transfonteiriço quanto às possibilidades de ação e ganho. Pouco se fala, porém, em "endurecer" as bolsas de valores. Os discursos de criminalização e repressão estão apoiados em códigos jurídicos de diversas escalas, motivados mais pela reserva de mercado e ampliação dos lucros do que pela preocupação com os cofres do governo e a segurança da população.

As empresas transnacionais no Brasil demandam barreiras tributárias e sanitárias mais altas, denunciando triangulação e contrabando, mas movimentam formulados e ativos entre fronteiras. Os mesmos agentes que atuam na formulação de leis não se restringem por elas, realizando tanto operações que se enquadram quanto que extrapolam a lei (por um lado, atacam o contrabando, por outro sonegam impostos).

Outro ponto importante a resgatar é a formação das leis. Ainda que a distinção entre o legal e o ilegal seja clara, desenhada por leis, normativas e regras, o arcabouço 
regulatório não é estático, sempre é renegociado em resposta às demandas dos diferentes grupos.

A discussão deixa claro que estamos falando de um state-making-process, sempre feito e reproduzido pelo discurso por vezes contraditório (e seus efeitos estruturantes e estruturas) e não de um ente essencializado.

Nesse deslizamento entre os mercados legal e ilegal, a territorialidade estatal é instrumentalizada através dos nacionalismos das transnacionais, de operações de triangulação de produtos no comércio internacional, sempre recorrendo à fronteira para a construção do valor legal e mercadológico do agrotóxico.

\section{REFERÊNCIAS}

ANDEF. O que é importante saber sobre defensivos agrícolas. Disponível em: http://tinyurl.com/ bwg3jeq . 2011a. Acesso em: 14 dez. 2011.

ANDEF. A Instituição. 2011b. Disponível em: http:/ / tinyurl.com/cj5x77h . Acesso em: 14 jun. 2012.

BECCARIA, Cesare. Ensayo analítico sobre el contrabando. Revista de economia institucional, v. 6, no 10 , p. 229-230, reprint de publicação em espanhol de 1822

DAS, Veena; POOLE, Deborah. El estado y sus márgenes. Etnografías comparadas. Revista Académica de Relaciones Internacionales, 8, p. 1-39, 2008.

DORFMAN, Adriana. Fronteira e contrabando em Sant'Ana do Livramento (BR)-Rivera (UY). Boletim Gaúcho de Geografia, no 32. Porto Alegre, Associação dos Geógrafos Brasileiros, Seção Porto Alegre, p. 75-92, 2007.

DORFMAN, Adriana. Contrabandistas na fronteira gaúcha: escalas geográficas e representações. Tese de Doutorado, Universidade Federal de Santa Catarina. Centro de Filosofia e Ciências Humanas. Programa de Pós- Graduação em Geografia. 2009.

DORFMAN, Adriana; REKOWSKY, Carmen. Geografia do contrabando de agrotóxico na fronteira gaúcha. Revista Geografica de America Central (Online), v. 2, 2011.

DORFMAN, Adriana; PRYTOLUK, Miguel Belardinelli; SEBASTIÃO, Rafael Machado. Estratégias de Pesquisa sobre o contrabando. Revista GeoPantanal. v. 6, no.11, p. 33-46, 2011.

DOU. Lei n. 7.802/89, de 11 de julho de 1989: Sobre agrotóxicos, seus componentes e afins. Diário Oficial [da] República Federativa do Brasil, 1989. Disponível em: http://tinyurl.com/ctzqvwf. Acesso em: jan. 2010.

EGLER, C. Mercosul: um território em construção? Ciência e Cultura, 58, 1, 2006.

FAO. Rotterdam Conventionon the Prior Informed Consent Procedure for Certain Hazardous Chemicals and Pesticides in International Trade. Roma: Secretaria da Convenção de Rotterdam,1998.

FAO. International Code of Conduct on the Distribution and Use of Pesticides. Roma: FAO, 2002.

FOUCAULT, Michel. The History of Sexuality, Volumen 1: An Introduction. Traduzido por R. Hurley. Random House, Nova Iorque, 1976.

HAESBAERT, Rogério. Des-territorialização e identidade: a rede "gaúcha" no Nordeste. Niterói: EdUFF, 1997.

HOFMANN, R. M. et al. A inserção do Brasil no comércio internacional de agrotóxicos - 2000-07. Indicadores Econômicos FEE, v. 38, nº 1, p. 103-128, 2010.

IBAMA. Produtos agrotóxicos e afins comercializados em 2009 no Brasil: uma abordagem ambiental. Brasília: IBAMA, 2010. 
MERCOSUL. Resolução 48/96: Requisitos para la libre circulación de productos fitosanitários em la etapa actual de integración del MERCOSUR. Buenos Aires: Mercosul, 1996a.

MERCOSUL. Resoulução 87/96: Procedimentos de inscrição para a livre circulação das substâncias ativas de grau técnico e/ ou suas formulações de produtos fitossanitários. Brasília: Mercosul, 1996b.

MERCOSUL. Resolução 149/96: Interpretação da Resolução no 48/96. Fortaleza: Mercosul, 1996c.

MERCOSUL. Resolução 156/96: Segunda Lista de substâncias ativas e suas formulações de livre comercialização entre os estados partes do MERCOSUL. Fortaleza: Mercosul, 1996d.

MERCOSUL. Resolução 71/98: Terceira lista de substâncias ativas e suas formulações de livre circulação entre os estados-partes do MERCOSUL. Rio de Janeiro: Mercosul, 1998.

MERCOSUL. Controversia entre la República Argentina y la República Federativa del Brasil sobre ‘Obstaculos al ingreso de productos Fitosanitarios Argentínos em el Mercado Brasileño. No incorporación de las Resoluciones GMC 48/96, 87/96, 149/96, 156/96 y 71/96 lo que impide su entrada em vigencia em le MERCOSUR'. MercosuL, 2002.

MDIC. Balanço geral da União. 2003. Disponível em http://tinyurl.com/c2a3hbc . Acesso em: jun. 2012.

MDIC. Dumping. Disponível em: http://tinyurl.com/bncw5vh . Acesso em: mar. 2012

MST. Campanha contra o uso de agrotóxicos. 2012. Disponível em http://tinyurl.com/3rh7nv2 . Acesso em: jan. 2012.

RACINE, J.-B.; RAFFESTIN, C.; RUFFY, V. Escala e ação: contribuições para a compreensão do mecanismo de escalas na prática da Geografia. Revista Brasileira de Geografia, 45, 1, p. 123-135, 1983.

SAMPAIO, Ivan Amâncio. O mercado brasileiro de defensivos agrícolas: principais países fornecedores. 2011. Disponível em http:/ / tinyurl.com/c82lhep . Acesso em: nov. 2011.

SHELTON, Dinah. International Law and 'Relative Normativity'. In: EVANS, M. (ed.). International Law, p. $145-72,2003$

URUGUAY. Decreto No 482/009 del 19 de octubre de 2009. 2009. Disponível em: http://tinyurl.com/ bnr44zc Acesso em: jan. 2012.

WHO. The WHO Recommended Classification of Pesticides by Hazard. Roma: WHO, 2009.

WHO. Pesticides. 2012. Disponível em: http:/ / tinyurl.com/7dfrqu8 . Acesso em: jul. 2012

Recebido em 24-12-2012

Aceito para publicação em 31-01-2014 